\title{
Pulmonary arteriovenous malformation: a rare cause of dyspnoea on exertion
}

\author{
Ankit Mangla, ${ }^{1}$ Alana Nevares, ${ }^{1}$ Naser Yamani, ${ }^{1}$ Najamul Ansari ${ }^{2}$
}

${ }^{1}$ Department of Internal medicine, John H Stroger Hospital of Cook County, Chicago, Illinois, USA

${ }^{2}$ Department of Cardiology, John H Stroger Hospital of Cook County, Chicago, Illinois, USA

\section{Correspondence to} Dr Ankit Mangla, ankit. mangla.md@gmail.com

Accepted 31 March 2014

\section{DESCRIPTION}

Pulmonary arteriovenous malformation (PAVM) is caused by the abnormal connection between pulmonary arteries and venous systems. First described in 1897 by Churton, PAVM is a rare disease. In an autopsy study in 1953 at Johns Hopkins, only 3 cases of PAVM were detected out of 15000 consecutive autopsies. ${ }^{1}$ PAVM are present in 15-50\% of patients with hereditary haemorrhagic telangiectasia (HHT), ${ }^{2}$ also known as Osler-Weber-Render disease; however $70 \%$ cases of PAVM are associated with HHT. ${ }^{1}$

A 69-year-old woman with a history of hypertension, diabetes, dyslipidaemia and hypothyroidism presented with a history of progressively increasing dyspnoea on exertion over past 3 months. She denied any history of chest pain, palpitations, presyncope or syncope. At admission pulse oximetry showed $83-90 \%$ saturation on room air, correcting to $95-96 \%$ on supplemental oxygen. Physical examination was significant for a faint bruit on right infrascapular region. Arterial blood gas (ABG) showed elevated Alveolar-arterial (A-a) gradient of $44.1 \mathrm{~mm} \mathrm{Hg}$ (normal for age was $17 \mathrm{~mm} \mathrm{Hg}$ ). Chest X-ray (CXR) showed a $3 \mathrm{~cm}$ tubular opacity in the right lower lobe (figure 1). CT angiogram confirmed the diagnosis of pulmonary arteriovenous malformation (AVM; figure 1). Two-dimensional
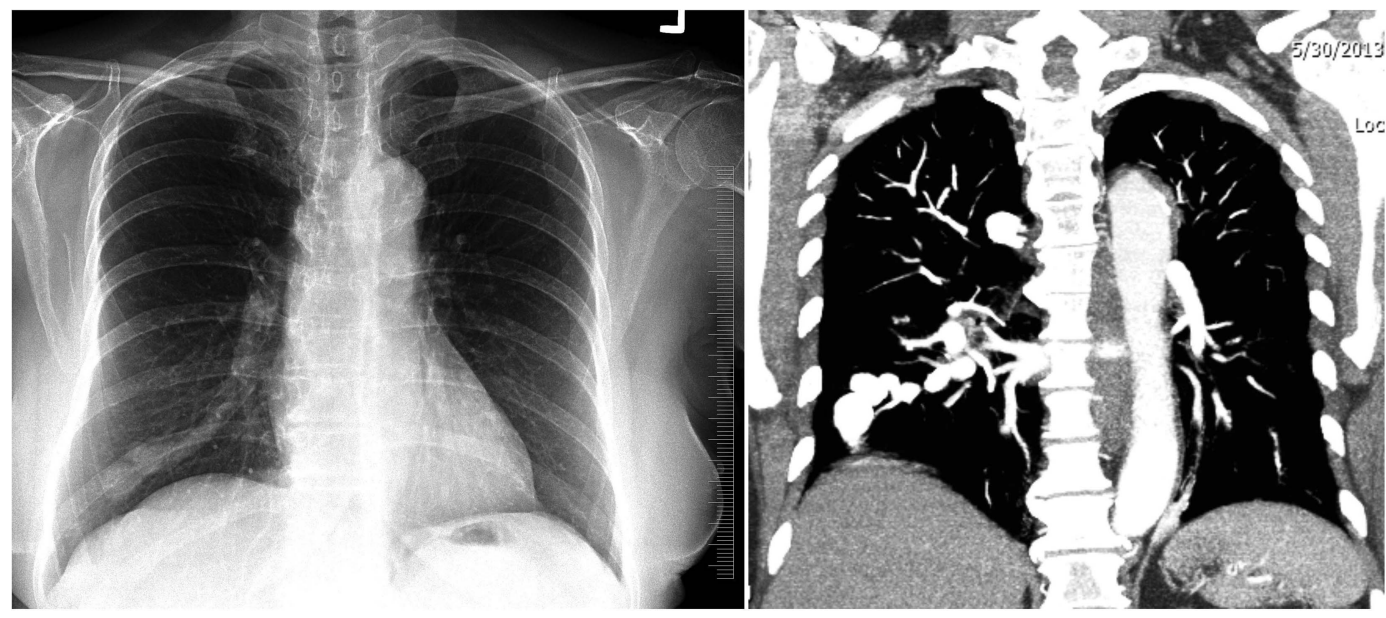

Figure 1 A $3 \mathrm{~cm}$ tubular opacity in the right lower lobe seen on the chest X-ray with connecting vessel from the hilum. Findings are replicated on the CT angiogram of the chest.
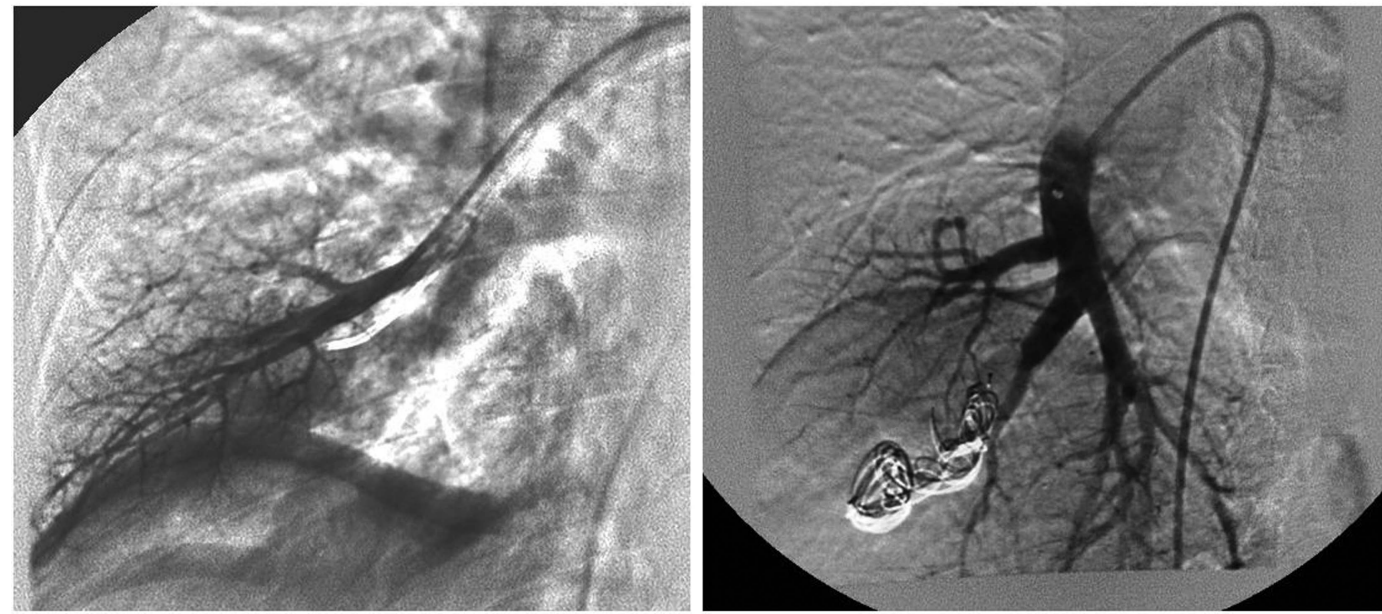

To cite: Mangla A,
Nevares A, Yamani N, et al BMJ Case Rep Published online: [please include Day Month Year] doi:10.1136/ bcr-2014-204087

Figure 2 Magnified view of digital subtraction pulmonary angiogram (left) demonstrating the angioarchitecture of the pulmonary arteriovenous malformation. After embolotherpay using multiple 0.035 inch coils (right) the pulmonary arteriovenous malformation is totally occluded. 
transthoracic echocardiogram showed normal ejection fraction and no anatomical abnormality. She underwent pulmonary angiography and subsequent occlusion of the PAVM with multiple

\section{Learning points}

- Dyspnoea is the most common lung symptom in patients with pulmonary arteriovenous malformation (PAVM). ${ }^{3}$ Hypoxaemia at presentation along with incomplete correction with supplemental oxygen and elevated Alveolar-arterial gradient should alert the clinician towards a right to left shunt and a possible PAVM.

- Transthoracic contrast echocardiography with agitated saline is the best screening test to detect PAVM whereas chest $\mathrm{X}$-ray is more specific in detecting PAVM. ${ }^{2}$ All positive finding should be confirmed with multidetector thoracic $\mathrm{CT}$ (MDCT) with thin cut $\left(1-2 \mathrm{~mm}\right.$ ) reconstructions. ${ }^{2}$ In the present era, the utility of pulmonary angiography is restricted to treatment only. ${ }^{3}$

- Treatment must be offered to all symptomatic patients whereas asymptomatic patients, especially children should be evaluated on case to case basis. ${ }^{2}$ Embolisation is the intervention of choice whereas surgery is reserved only for patients with fatal haemorrhages. ${ }^{2}$ Follow-up with MDCT at 6-12 months must be performed to detect reperfusion of PAVM and opening up of occult PAVM. ${ }^{2}$ $0.035^{\prime \prime}$ Mreye embolisation coils (figure 2), leading to closure of PAVM. Postprocedure her saturation rose to $96-98 \%$ on room air and exercise tolerance continues to improve at follow-up. Screening colonoscopy did not show any AVM and she is awaiting screening CT angiogram of the brain and esophagoscopy for the detection of occult AVM.

Acknowledgements The authors thank the entire department of Intervention Radiology at John H Stroger Jr Hospital of Cook County for cooperating and guiding us in our endeavour.

Contributors AM wrote and rewrote the manuscript as per recommendations. AN sought the appropriate references and revised the manuscript as per reviewers comments. NY provided the images and gave critique to the manuscript. NA attended the case and helped develop the manuscript by providing expert opinion and critique.

Competing interests None.

Patient consent Obtained.

Provenance and peer review Not commissioned; externally peer reviewed.

\section{REFERENCES}

1 Gossage JR, Kanj G. Pulmonary arteriovenous malformations. A state of the art review. Am J Respir Crit Care Med 1998;158:643-61.

2 Faughnan ME, Palda VA, Garcia-Tsao G, et al. International guidelines for the diagnosis and management of hereditary haemorrhagic telangiectasia. J Med Genet 2011;48:73-87.

3 Cottin V, Chinet T, Lavole A, et al. Pulmonary arteriovenous malformations in hereditary hemorrhagic telangiectasia: a series of 126 patients. Medicine 2007:86:1-17

Copyright 2014 BMJ Publishing Group. All rights reserved. For permission to reuse any of this content visit http://group.bmj.com/group/rights-licensing/permissions.

BMJ Case Report Fellows may re-use this article for personal use and teaching without any further permission.

Become a Fellow of BMJ Case Reports today and you can:

- Submit as many cases as you like

- Enjoy fast sympathetic peer review and rapid publication of accepted articles

- Access all the published articles

- Re-use any of the published material for personal use and teaching without further permission

For information on Institutional Fellowships contact consortiasales@bmjgroup.com

Visit casereports.bmj.com for more articles like this and to become a Fellow 